\title{
The Scope and Limitations of Legal Protection of Chinese Foreign Investments in Lusophone Markets and the Role of Macau Society
}

\author{
M. P. Ramaswamy
}

Faculty of Law, University of Macau

\begin{abstract}
The paper examines the significance of legal protection of Chinese Foreign Investments in Lusophone markets with a specific reference to Bilateral Investment Treaties (BITs) with Cape Verde and Portugal and assesses how Macau SAR as a Lusophone society could play a positive role in facilitation of foreign investments. With the keen Chinese interest on Lusophone markets and its official designation of Macau as a facilitator, most studies have been focused on broader economic relations with them as a group and the present paper investigates the scope of legal protection in certain specific bilateral investment relations. The paper comparatively examines the scope of legal protection of Chinese investments in two sets of Lusophone markets namely those which have no BITs with China and those which have succesfully concluded the BITs (particularly Cape Verde and Portugal). Based on the analysis, key limitations and some potential barriers to bilateral investment flows are highlighted. The final part of the paper scrutinizes how Macau SAR could contribute to enhance investment flows between China and Lusophone markets, especially in the light of its legal system with a Portuguese influence. The paper concludes with a discussion on the need and viability of a regional investment protection and facilitation agreement under the auspices of the Forum Macau to address the identified challenges and promote the utitlity of related legal and other allied services Macau society could offer. ${ }^{1}$
\end{abstract}

Keywords: China-Lusophone bilateral investments, treatment of investments, scope of legal protection, role of Macau society

\section{Introduction}

Lusophone countries or Portuguese Speaking Countries have been markets of keen interest for foreign investors. Although the degree of attraction of individual markets differ from each other and the level of foreign investments in each of these markets vary in different years, the general attraction of the group of Lusophone countries as an investment destination is robust. China is no exception and it has indeed demonstrated a conspicuous interest in Lusophone markets as a part of its strong drive towards international economic engagement (Macau Hub, 2018). This is clearly evidenced by two concrete initiatives introduced by China, namely the creation of a permanent ministerial forum to facilitate economic and trade cooperation with Lusophone countries and the creation of a development fund exclusively targeting the Lusophone economies. However, despite the attractiveness of the Lusophone markets and the concrete initiatives made to promote trade and economic relations with the them, the efforts to secure legal protection of bilateral investments between China and Lusophone markets have been quite limited. Out of the eight prominent Lusophone economies, China has only successfully concluded bilateral investment treaties (BITs) with only three of them and the potential effectiveness of those instruments requires a systematic assessment (Salacuse, 2007). The resulting limitations of legal governance of bilateral investments between China and Lusophone markets could create various barriers in tapping the full investment potential offered by these markets for each other (Poulsen, 2010). In the light of this concern, the present paper seeks to identify the the scope and limitations of legal protection of China-Lusophone bilateral investments to urge the need to develop relevant

\footnotetext{
${ }^{1}$ The author would like to acknowledge and thank the support of the University MYRG project grant related to the paper.
} 
remedial measures to promote mutual investments. The paper also briefly explores the potential role Macau SAR could play in facilitating the bilateral investments, as it has been officially designated with such a responsibility by China.

\section{Legal Governance of Chinese Investments in Lusophone Markets}

According to the data relating to International Investment agreements provided by the United Nations Commission on Trade and Development (UNCTAD), out of 234 listed economies in the world, China has the second highest number of concluded bilateral investment treaties as well as the third highest number of those treaties in force. As of April 2019, China has signed a total number of 127 bilateral investment treaties, and out of which 109 treaties are in force. Only Germany has a higher number of signed BITs with a total of 131 treaties and Germany as well as Switzerland having a higher number of such treaties in force which are at 128 and 112 respectively (UNCTAD, IIAs by Economy, 2019). Since 1998 China's BIT practice is said to have been "marked by a gradual yet decisive shift towards stronger substantive and procedural protection of FDI". (Berger, 2008 October, p.21). These clearly evidences the fact that China attaches a great importance to the legal protection of foreign investments despite being a developing country. Therefore, it is important to assess the Chinese foreign investment relations with any country in the light of this fundamental premise. However, the review of the bilateral legal measures governing investment relations with lusophone economies reveals an unsatisfactory situation. Out of the eight prominent Lusophone economies, China has signed bilateral investment treaties only with three of them. (UNCTAD, China BITs, 2019). While BITs have been signed with Cape Verde, Mozambique and Portugal, China is yet to have such treaties with the remaining five Lusophone economies.

Evidence suggests that the five Lusophone economies, which do not have any BITs with the China generally tend to be reluctant in entering in to BITs with foreign countries. All five of these economies have entered into BITs only with a handful of foreign states and even most of those signed BITs are yet to enter into force. Angola having entered into 13 BITs with different foreign countries, has only 5 of them in force. The experience of Brazil reveals a much worse situation as out of the $22 \mathrm{BITs}$ signed by Brazil only one has entered into force (Campello \& Lemos, 2015). Guinea Bissau has 2 BITs to its credit with one enjoying Force. San Tome and Principe, on the other hand, draws a blanc with no BITs in force albeit having two of them signed. Finally, East Timor has 3 BITS with one already entered into force.

Inspite of the general grim picture emerging, a closer instrospection of the limited number of BITs concluded by these five economies reveals an interesting finding which signifies the specific importance they attach for establishing legal framework governing foreign investment with other Lusophone economies. All these five countries have signed BITs with atleast one or more Lusophone countries. Angola has signed BITs with Brazil, Cape Verde, Mozambique and Portugal. Out of the four concluded Angolan BITs with Lusophone economies, only two of them have entered into force namely the Angola-Brazil BIT and the Angola-Cape Verde BIT. It is important to note that the Angola-Cape Verde BIT stands out for its most rapid entry into force, which was within a span of four months since it was concluded in September 1997 (emphasis added). However, it is relevant to note that Angola has attempted two BITs with Portugal in 1997 and 2008 respectively but none have entered into force. Similarly, the Angola-Mozambique BIT concluded in 2015 is yet to enter into force.

Brazil has signed BITs with three of the Lusophone economies that includes Angola, Mozambique and Portugal. It is interesting to note that in case of Brazil, the first and the only BIT that has entered into force in its long list of 22 concluded BITs is with a Lusophone economy namely Angola. Out of the two BITs signed by Guinea Bissau, one of them is concluded with Portugal. It is significant to note that the Guinea Bissau-Portugal BIT has already entered into force since 1996. Similarly, San Tome and Principe has signed a BIT with Portugal, which is one of the two total BITs it has signed with foreign countries. However, unlike the earlier example of Guinea Bissau, the San Tome and Principe's BIT with Portugal has not entered force yet, inspite of being concluded way back in 1995. Finally, East Timor has, out of its three BITs concluded, one signed with Portugal. Interestingly, it is the only BIT that has entered into force for Timor. The East TimorPortugal BIT was signed in May 2002 and entered into force in April 2004. 
The number of Chinese BITs signed with Lusophone countries, inspite of being limited, reveals a striking positive feature that all those BITs have already successfully entered into force. Among the three Chinese BITs concluded with Lusophone economies, the China-Mozambique BIT signed in July 2001 was the quickest to enter into force within a span of eight months. In contrast, the China-Cape Verde BIT concluded in April 1998 as well as the China-Portugal BIT concluded in December 2005 took more than two and a half years to enter into force. Although the entering into force of a BIT is crucial, it is important to closely examine the normative characteristics of the individual BITs in order to understand scope and limitation of the legal protection they offer as well as their potential to facilitate and promote bilateral investment flows between contracting states (Salacuse \& Sullivan, 2005). To carry out such an assessment in the context of ChinaLusophone bilateral investment relations, the next sections closely examines the China-Cape Verde BIT 1998 and the China-Portugal BIT 2005 as they are representative of not only two different periods but also Lusophone economies in two different continents and levels of development. The periodic perspective is particularly relevant as scholars studying Chinese BITs have argued that they have evolved over different periods and possess typical characteristics. Classifying Chinese BITs into different generations of $80 \mathrm{~s}, 90 \mathrm{~s}$, and subsequent decades in the $21 \mathrm{st}$ century are common and is useful a guide to compare and assess the characteristics of individual BITs involving China (Berger, 2008) and (Kidane, 2016).

\section{Assessment of the Legal Regime Governing China-Cape Verde Bilateral Investments}

The China-Cape Verde BIT 1998 in its very title has incorporated the key terms of 'encouragement and reciprocal protection of investment', which signifies the dual objectives of investment promotion and protection. Its Preamble, however, uses the terms 'encouragement and promotion' separately, which arguably could be seen distinctively due to the possibility of tracing specific obligations stemming from these two objectives in the subsequent parts of the BIT. The intention of concluding the BIT is aimed at developing favourable conditions for mutual investments. The Preamble expresses the belief that the encouragement, promotion and protection of reciprocal investments will creative conducive environment to stimulate business initiatives by investors, which in turn will result in mutual prosperity of both countries. Finally, the Preamble proclaims that the principles of 'equality' and 'mutual benefits' as the fundamental basis upon which the desire for the investment cooperation is built and the norms constituting the BIT have been agreed. The scope of the investments covered in the BIT is broad. Although the indicative forms of investment are listed, the BIT for all practical purposes includes every kind of asset legally invested in the host country1.

Unlike some BITs that narrowly define investments or exclude some specific forms of investments from the definition, the broad narrative of investment in the China-Cape Verde BIT could help avert any potential disputes regarding its scope of application to protect specific forms of investment between the two countries. The definition of the term investor refers to natural and legal persons with certain qualifications. While natural persons could qualify as investors by possessing the nationality of either of the contracting states, the qualification for economic entities requires establishment in accordance with the laws of a contracting state and domicile therein.

The obligations emanating from certain objectives of the BIT discussed earlier includes the obligation to 'encourage' investors from the other contracting state, obligation to admit resulting investments, obligation to provide constant protection and security for such investments, obligation to refrain from taking any unreasonable or discriminatory measures against those investments as well as a specific obligation to facilitate the obtaining of visas and working permit to each other's nationals necessary for relevant investment activities ${ }^{2}$.

\footnotetext{
1 Interestingly, the indicative list includes investments in the forms of shares, stocks and other company participations as well as certain intellectual properties including know-how and related processes. It is equally important to underscore the fact that the list explicitly includes concessions, particularly "concessions to search for exploit natural resources". See Article 1 (e) of China-Cape Verde BIT, 1998.

2 See Article 2, China-Cape Verde BIT, 1998.
} 
The treaty mandates a fair and equitable treatment of investments along with their protection on a most favoured nation (MFN) ${ }^{1}$ basis. However, the MFN obligation does not apply to any preferential treatment accorded to the investors of a third State due to obligations arising from regional free trade agreements or avoidance of double taxation agreements. The BIT generally prohibits expropriation, nationalization or similar measures unless they are introduced for the purpose of securing public interest. Even when those acts of the state are justified, they should be carried out according to the established legal procedures and in a non-discriminatory manner. In addition, a payment of fair compensation for the above acts is mandatory. Such compensation should be made in a timely manner and be convertible and freely transferrable by the investor. Moreover, the contracting states are obliged to guarantee the investors, the freedom to repatriate relevant investments and returns at the prevailing exchange rate on the date of transfer ${ }^{2}$. If a contracting state or it's agency makes any payment to an investor on the basis of a guarantee granted to an investment made in the territory of the other contracting state, the treaty interestingly obliges the other contracting state to recognize the right of subrogation of the former state (which made the payment) ${ }^{3}$.

Finally, different means of settling disputes arising out of the treaty are recognized. Two categories of dispute settlement are foreseen, namely disputes between the contracting states to the BIT and dispute between an investor protected under the treaty and a contracting state. Firstly, the disputes between the contracting states related to the interpretation or application of the BIT are required to be settled using consultation through diplomatic channels. Ad hoc arbitration is prescribed as a method if such disputes could not be settled within six months using the diplomatic means 4 .

Secondly, the treaty prescribes a separate set of dispute settlement provisions for investment disputes between an investor and a contracting state. After prescribing negotiations as the preliminary method to be tried for a period of six months for all types of investment disputes, the treaty recognizes two distinct methods for general investment disputes and investment disputes concerning the amount of compensation for expropriation respectively. For general investment disputes between the investor and the host state, the treaty recognizes the entitlement of the investor to submit the disputes to the competent court of the host state. But if such disputes are related to the amount of compensation for expropriation, the treaty recognizes the right of either of the party to the dispute to resort to ad-hoc arbitration.

While the parties to the dispute could nominate their respective arbitrators ${ }^{6}$, either of them could request the Secretary General of the International Center for Settlement of Investment Disputes (ICSID) to make the necessary appointments, if the arbitration panel could not be constituted within a prescribed period. Similarly, the treaty recognizes the freedom of the arbitration tribunal to take guidance from the ICSID Arbitration Rules in determining its own arbitration procedure to resolve the dispute. Moreover the treaty mandates the arbitration tribunal to decide the dispute in accordance with an explicit set of 'sources of law' recognized in the treaty which includes a) the law of host state including its rules on the conflict of laws

\footnotetext{
1 The treaty also obliges the contracting states to afford treatment on an MFN basis, whenever they introduce any measures impacting investors who suffer losses owing to war, national emergency, insurrection, riot or other similar events. See Article 5, China-Cape Verde BIT, 1998.

2 Investments and returns under this obligation cover a broad range of items explicitly enlisted in the treaty, which not only includes the profits but also various forms of earnings, types of payments and other legitimate income.

3 This arises because of a mandate that the other contracting state must recognize 'the transfer of any right or claim of the investor' (who was paid) to the former contracting state or its agency.

${ }^{4}$ The BIT also prescribes the procedure for appointment of the arbitrators and how the tribunal could determine the arbitrations procedure. In this context, the possibility of seeking the assistance of a judge of the International Court of Justice to nominate an arbitrator in certain circumstances is also recognized.

${ }^{5}$ However, these provisions do not apply in cases where the disputing investor has already resorted to the national courts of the host state to resolve the dispute relating to the amount of compensation subsequent to the failure of relevant negotiations mandated by the treaty.

${ }^{6}$ While the power to select the Chairman of the arbitration panel is jointly conferred on the two arbitrators nominated by the parties to the dispute, the treaty requires the choice of the Chairman to be a national of a third state that has diplomatic relations with both the China and Cape Verde.
} 
(private international law rules of the host state) b) the provisions of the BIT and c) the general principles of (public) international law accepted by both contracting states to the treaty.

Interestingly, the treaty adds that in case of the treatment to be accorded to the relevant investments under the domestic law of a contracting state is more favourable that the treatment recognized in the BIT, the more favourable treatment under the domestic law shall become applicable. This is particularly useful when the domestic law evolves to offer a better protection than a BIT that was concluded quite some time ago. For example, the Chinese investors could seek the benefits offered by the new Investment Code Law of Cape Verde (Law 13/VIII/2012) by virtue of this provision enshrined in the China-Cape Verde BIT (Johnson, 2012). Finally, the BIT obliges the contracting states to hold regular meetings to review its implementation, exchange legal information and investment opportunities, resolve investment disputes, forward proposals on investment promotions and study other investment related issues. This obligation for continuous consultation between the parties to promote the fundamental objectives of the BIT is crucial to keep the investment cooperation alive and meaningful in the long run.

\section{The Distinctive Legal Characteristics of China-Portugal BIT and Perceived Limitations}

After the identification of the major scope of Chinese BIT with Cape Verde, it is relevant to discuss the key features of the China-Portugal BIT in order to understand whether there is any distinctive approach in protecting and promoting Chinese investment. This curiosity arises not only because Portugal is a Lusophone state outside Africa and is at a different level of economic development but also because of the succession of a new generation investment treaty replacing the older BIT between the two states. The original BIT signed between China and Portugal in 1992 was replaced by a new generation BIT signed in December 2005 that came into effect in July 2008. Analysing the key distinctive features of this new BIT is crucial to assess the scope of the legal protection afforded to the bilateral investments between the two states.

In comparison with the China-Cape Verde BIT 1998, the title and preamble of the China-Portuguese BIT is similar except the later does not refer to the 'principles of equality and mutual benefit' explicitly in the preamble as the former does. However, the China-Portuguese BIT 2005 provides an expanded definition of key terms. The term investment is defined to include assets that are invested directly or indirectly, and specific types of investments enlisted in the definition also have expanded provisions ${ }^{1}$. For example, patents and trade-marks, trade/business secrets and even good will are recognized a part of investments. Similarly, the category of concessions granted by administrative act and concession to cultivate and extract natural resources are added to the definition. Moreover, a new category involving goods under a leasing agreement placed at the disposal of a lessee is also recognized as an investment. The definition of the term investment also clarifies that any change in the form of the invested assets does not affect their character as investments.

In defining the term 'investor', the China-Portuguese BIT takes an interesting approach as it provides a separate definition for investors emanating from each of the two contracting states. While the investors of the both states include natural and legal persons, the latter category is defined differently for the two states. Certain distinctive features, and specific requirements and characteristics could be noted. Especially the investor in the context of China is defined as 'economic entities' not only incorporated and constituted under the Chinese law but also have their seats China. Moreover, such entities could either be for profit or non-profit and with or without limited liability.

In defining the term 'return', the China-Portuguese BIT adds that any income arising from reinvested returns of the original investments should also treated as the income related to the original investment. Finally, an additional term namely 'territory' is defined, which interestingly enumerates various spaces that typically fall within the sovereign control of state under international and national laws. This includes the area of sea bed and subsoil adjacent to the outer limit of the territorial sea of the home state. This attempt to add an explicit definition of territory could be seen an evolution of the modern BITs to

\footnotetext{
${ }^{1}$ However, some categories have a more restricted definition like the 'claims to performance having an economic value' is now specifically limited to such claims associated with an investment. See Article 1 (1) (c), China-Portugal BIT 2005.
} 
comprehend potential investments in various territorial parts of a home state, where foreign investments were not typical in the past. However, in a more globalized and technologically advanced contemporary world, any part of a state territory could trigger foreign investment interest. Therefore, a comprenhensive definition of the term territory is warranted.

With regard to the treatment of investment, the China-Portuguese BIT while containing similar provisions like the ChinaCape Verde BIT adds a new principle of national treatment, which mandates the home state to afford treatment no less favourable than it accords to investments and associated activities by its own domestic investors ${ }^{1}$. Although the provisions restricting expropriation are prescribed in a similar manner in both BITs, the rules governing compensation arising out of any expropriation are more specific and detailed in China-Portuguese BIT. Firstly, it requires that the compensation should be equivalent to the market value of the expropriated investment at the time immediately before the act of expropriation or at the time when the plan for expropriation become public knowledge, whichever is earlier. It also dictates that generally recognized principles of valuation shall be employed in determining the market value.

In addition, the new BIT also obligates the payment of interest at commercial rates for the period between the expropriation and the payment of compensation. Strikingly, the China-Portuguese BIT recognizes a distinct right of the investor to seek prompt review of its case (including the issue of valuation and payment of compensation) by a judicial or other independent authority of expropriating state based on the relevant principles of the $\mathrm{BIT}^{2}$.

On the issue of repatriation of investment and returns, the explicit list of investment and returns to which the host state is required to provide a guarantee of repatriation is different from the parallel provisions in the China-Cape Verde BIT. Moreover, the repatriation should be permitted at the prevailing market rate of exchange applicable in the host state on the date of transfer and the BIT also prescribes the method of determining the rate of exchange in the event if the market rate of exchange does not exist. While providing similar provisions governing the 'right of subrogation' of a contracting state to the treaty, the China-Portuguese BIT adds that any payment received by virtue of the subrogated claims shall also enjoy the right of repatriation according to the relevant principles recognized in the BIT.

The dispute settlement provisions related to disputes between the contracting parties to the treaty are prescribed similarly by the China-Portuguese BIT. However, it provides a fundamentally different set of provisions governing investor-state disputes arising from the BIT. First, the distinction between general investment disputes and the specific dispute relating to the amount of compensation for expropriation found in the China-Cape Verde BIT is done away with. Secondly, the provisions prescribing the obligation to seek amicable settlement between the disputing parties does not explicitly refer to the use of negotiations, which implies an intention to encourage the use of alternative means like conciliation or mediation to reach the desired solution (UNCTAD, 2010). Finally, and most importantly, the China-Portuguese BIT now provides the investor with an exclusive freedom to choose three effective channels of dispute settlement. The dispute could be submitted to either the competent court of the contracting state involved in the investment dispute or the ICSID Arbitration or an adhoc arbitral tribunal ${ }^{3}$. The China-Portuguese BIT also limits the application of its provisions only to those 'disputes' arising subsequent to the entry into force of the BIT albeit recognizing the possibility of its application to 'investments' made prior to the said entry into force of the BIT.

The obligation to hold periodical meetings between the contracting states to promote specific purposes recognized under the China-Cape Verde BIT is found to have been quite diluted under the China-Portuguese BIT. It only recognizes the

\footnotetext{
${ }^{1}$ In addition, similar national treatment is also warranted in the context when investors suffer losses in the host state due to war or other armed conflict, revolution, national emergency or revolt. See Article 5 of the China-Portugal BIT 2005.

2 See Article 4 (3) of the China-Portugal BIT 2005.

${ }^{3}$ Such ad-hoc arbitration tribunal could be established either under the Arbitration Rules of the United Nations Commission on International Trade Law (UNCITRAL) or other arbitration rules. See Article 9 (2) (c) of the China-Portugal BIT 2005.
} 
possibility of a state party making a proposal to request consultation for a limited set of purposes ${ }^{1}$ and recommends that such a proposal be accorded sympathetic consideration by the other state party.

Apart from various limitations identified while comparatively analysing the China-Portuguese BIT in the above paragraphs, it is important to note that China and Portugal have added a separate protocol attached to the BIT, which further qualifies and narrows the scope of application of the provisions of the BIT2 ${ }^{2}$. Although the space limits the possibility to discuss the provisions of the protocol one by one, some of the key limitations arising from such provisions must be noted in order to assess the true scope of the China-Portuguese BIT.

The limitations are mainly recognized with regard to the obligations arising for China under the BIT and are specifically related to provisions of the BIT governing potential measures against the management, maintenance, use, enjoyment and disposal of the investments under its Article 2, national treatment to foreign investments under Article 3, repatriation of investments and returns under Article 6 and the right of a Portuguese investor in China to resort to Arbitration under Article 9. As these restrictions mainly pertain to China as a host state, it evidences the growing strength of China to successfully negotiate required carve out provisions with a developed contracting state like Portugal. More importantly, it should also be considered as a sign of positive cooperation between the two contracting states that are willing to recognize domestic sensitivities and providing for necessary flexibilities to ensure the success of the BIT ${ }^{3}$.

\section{Macau SAR as a Facilitator of Economic Relations between China and Lusophone markets and its Potential Role in Investment Facilitation}

Macau is a Special Administrative Region (SAR) of China. Macau enjoys legislative, judicial and other forms of autonomy under the 'one country-two systems' principle and is governed by a distinctive legal system. As a territory, which was under the Portuguese administration for a long period of history, its legal system has a strong influence of Portuguese legal tradition and characteristics. Due to this distinct advantage, China has officially designated Macau with the responsibility of promoting China's economic relations with the Lusophone countries. Macau has traditionally maintained strong ties with different Lusophone territories around the world. To provide a strong impetus to this mission, a Permenant Ministerial Forum for Promoting Trade and Economic Relations between China and Portuguese Speaking Countries (Forum Macau) has been established in Macau SAR since 2003. The Forum Macau has regularly held ministerial level conferences over the years resulting in different strategic planning to promote bilateral trade and economic cooperation in various frontiers including investment and development. Macau has also established strong legal ties with China including a Common Economic Partnership Arrangement (CEPA), an Arrangement on Reciprocal Recognition and Enforcement of Arbitration Awards, a Framework Agreement of Co-operation with Guangdong and an Arrangement on the Mutual Recognition and Enforcement of Civil and Commercial Judgments.

It is important to note that Macau by virtue of its freedom to enter into economic relations with other foreign markets has entered into a BIT with Portugal in 2000, which is inforce since May 20024. However, this freedom to independently enter into BITs with foreign markets, could arguably seen as a cause for the limitation of application or extension of China's BITs to the SAR. In the case of Sanum Investments Limited v. Government of The Lao People's Democratic Republic 5 , an investor from Macau SAR who made investment in Laos sought protection under the China-Loas BIT 1993. When the case

\footnotetext{
1 The request can be made for the purposes of interpretation, application and implementation of the BIT. See Article 13 of the ChinaPortugal BIT 2005.

2 It is equally relevant to note that some of the provisions of the Protocol clarifying the provisions of the BIT further could be seen as a positive element, which have the effect of facilitating the application of the provisions of the BIT to specific situations that have the potential avert some related disputes. See for example, Ad Article 1 and Ad Article 3 of the Protocol to the China-Portugal BIT 2005.

3 In this context, it is important to note that many of the restrictions recognized under the Protocol are to be gradually phased out by China.

${ }^{4}$ Macau has also been an independent member of the World Trade Organization (WTO) distinct from the membership of China. 5 [2016] SGCA 57
} 
was litigated in Singapore, a question arose whether China's BITs are applicable to the territory of Macau SAR. Although, the Singapore Court of Appeal decided that the BIT is applicable to Macau ${ }^{1}$, it was categorically denied by China through diplomatic notes (Mohan \& Aziz, 2018). It clearly explained the reasons for the non-application of such treaties based on the legal position enumerated under the Basic Law of Macau SAR as well as other relevant legal instruments and declarations governing the international legal status of the SAR. This recognized limitation should be noted in any assessment of the potential role of Macau SAR as a facilitator of economic relations between China and Lusophone countries. At the same time, the freedom Macau enjoys in entering into international economic relations as a distinct special administrative region of China should be given due credit in such assessments.

Due to the limitation of space in this paper, the specific advantages of Macau SAR that could potentially facilitate promotion of investments between China and Lusophone countries, especially in providing various legal services, could be taken up for discussion during the conference deliberations. However, one key development adding to the potential of Macau to effectively serve in that position merits a special mention. Apart from establishment of the Forum Macau that could serve as a primary platform for investment promotions, China has established the China-Portuguese Speaking Countries Cooperation and Development Fund, which not only serves as a large funding source but also provides for a well developed management system for project development, investment evaluation as well as legal compliance and risk control related to those investments. (CPD Fund, 2013). The Fund provides opportunities for companies from the member states to set up joint venture investments in the Lusophone markets. The Fund also contemplates the inclusion of the process of negotiating and concluding of relevant legal documents with investment partners specifying pertinent investment terms related to the supported investments. Interestingly, the fund that was originally setup in China has been moved to Macau SAR since 2017, which further enhances the potential role of Macau in promoting investments between China and Lusophone economies. This specific advantage of the location of the fund in Macau and related legal issues should also serve as one of the major considerations in any assessment of the investment promotion role of Macau.

\section{Conclusion and Recommendations}

The analysis in the paper is aimed at serving as a reference for the deliberations of a range of legal issues relating to investment promotion and protection between China and Lusophone countries. The underlying concerns and potential solutions for improvement resulting from the findings of this paper should be a subject of consideration in the conference deliberations. However, some preliminary concluding remarks and observations could be made here. As evidenced from the discussion, China has not established legal agreements governing bilateral investments with all Lusophone countries. It leaves some key Lusophone states like Brazil and Angola, which should be of a concern. Moreover, given the wider interest of China to establish cooperation with Lusophone states in general, initiatives to establish specific legal framework governing investments with smaller Lusophone economies is also needed to achive a comprehensive cooperation contemplated under the Forum Macau. The closer analysis in this paper of the scope and limitations of the legal regime governing bilateral instrument between China and Cape Verde as well as China and Portugal clearly indicates the wide range of legal obligations and guarantees that are crucial to ensure smooth and profitable mutual investments. The conspicuous absence of specific agreement on such obligation and guarantees leaves a big lacuna that can raise barriers to investment growth with the five Lusophone states that do not have BITs with China. The resulting situation creates the need to rely on the legal sources of domestic law of the five member states or general principles of international law. (Mouzinho, 2016). But these non exclusive sources may not effectively cater to the future promotion and protection of investment interest of China and other relevant Lusophone states. Even if the lack of initiatives to conclude BITs with the remaining five Lusophone countries in the past could be attributed to some justified reasons, constant review of the need and feasibility of conclusion of missing BITs should be carried out.

\footnotetext{
${ }^{1}$ However, it is relevant to note that the Singapore High Court previously came to the opposite conclusion before its decision was challenged at the Court of Appeal.
} 
In the absence of the establishment of any concrete legal regime governing investments with the five Lusophone countries, potential solutions could be seen with the Macau SAR assuming an active role. First of all, Macau's advantage of its legal system influenced by the Portuguese legal tradition could be effectively utilized to liaise with the situation of having to rely on the domestic law of the five Lusophone countries for purpose of investment protection. This could range from the possibility of using Macau as a platform to arbitrate investment disputes to more substantial use of Macau legal services. Moreover, the feasibility of concluding a comprehensive regional investment agreement involving all the Lusophone countries based on a set of common minimum standards agreeable to all members could be explored. Such instrument could also be designed to serve as a framework agreement for potential future BITs specifically with the five Lusophone countries. Finally, from the findings of this paper related to the advantages of the second-generation BIT concluded between China and Portugal, it is essential to revisit the need to upgrade the China-Cape Verde BIT (Huang, 2018). Moreover, the measures to address the limitations arising from the Protocol to the China-Portuguese BIT is also required, not only to serve the bilateral investments between the two contracting states better but also to use it as a potential model BIT for concluding investment promotion and protection agreements with other Lusophone countries.

\section{References}

[1] Berger, A. (2008, October). China and the Global Governance of Foreign Direct Investment: The Emerging Liberal Bilateral In-vestment Treaty Approach. Discussion Paper. German Development Institute. Retrieved from https://www.diegdi.de/uploads/media/DP_10.2008.pdf

[2] Berger, A. (2008, November). China's New Bilateral Investment Treaty Programme: Substance, Rational and Implications for International Investment Law Making. Paper Prepared for the Biennial ASIL IELIG Conference, Washington, D.C., November 14-15, 2008 retrieved from https://www.die-gdi.de/uploads/media/Berger_ChineseBITs.pdf

[3] Campello, D, \& Lemos, L. (2015). The Non-ratification of Bilateral Investment Treaties in Brazil: A Story of Conflict in a Land of Cooperation. Review of International Political Economy, 22 (5), 1055-1086.

[4] CPD Fund. (2013, June). China Portuguese Speaking Countries Cooperation and Development Fund. First Edition retrieved from http://www.forumchinaplp.org.mo/wp-content/uploads/2014/10/1.1-20cpdfund2013.compressed.pdf

[5] Huang, J. (2018). Procedural Models to Upgrade BITs: China's Experience. Leiden Journal of International Law, 31 (1), pp. 93-115.

[6] Johnson, C. (2012, August). Cape Verde: New Investment Code. Global Legal Monitor. Retrieved from http://www.loc.gov/law/foreign-news/article/cape-verde-new-investment-code/

[7] Kidane, W. (2016). China's Bilateral Investment Treaties with African States in Comparative Context. Cornell International Law Journal, 49 (1), 141-177.

[8] Macau Hub, (2018, May 28). China's investment in Portuguese-speaking countries reaches US $\$ 50$ billion. Retrieved from https://macauhub.com.mo/feature/pt-investimento-da-china-nos-paises-de-lingua-portuguesa-atingiu-50-mil-milhoes-dedolares/

[9] Mohan, M., \& Aziz, S. (2018). Construing a Treaty Against State Parties' Expressed Intentions: Sanum Investments Ltd v Government of the Lao People's Democratic Republic. Singapore Academy of Law Journal, 30, 384-416.

[10] Mouzinho, A. (2016, October). Understanding the Angolan FDI Regulatory Landscape, SAllA Occasional Paper No 238, pp.1-20.

[11] Poulsen, L. N. S. (2010). The Importance of BITs for Foreign Direct Investment and Political Risk Insurance: Revisiting the Evidence. In The Yearbook on International Investment Law and Policy 2009/2010 (pp. 539-574). New York: Oxford University Press.

[12] Salacuse, J. W., \& Sullivan, N. P. (2005). Do BITs Really Work: An Evaluation of Bilateral Investment Treaties and Their Grand Bargain. Harvard International Law Journal, 46(1), 67-130.

[13] Salacuse, J. W. (2007). The Treatification of International Investment Law. Law and Business Review of the Americas, 13(1), $155-166$.

[14] UNCTAD (2010). Investor-State Disputes: Prevention and Alternatives to Arbitration. UNCTAD Series on International Investment Policies for Development. (PP.1-129) Geneva: United Nations.

[15] UNCTAD (2019, April 30). IIAs by Economy. International Investment Agreements (IIA) Navigator. Retrieved from https://investmentpolicy.unctad.org/international-investment-agreements/by-economy 
[16] UNCTAD (2019, May 5). China Bilateral Investment Treaties (BITs). International Investment Agreements (IIA) Navigator. Retrieved from https://investmentpolicy.unctad.org/international-investment-agreements/countries/42/china 